\title{
Experimental Study of an Industrial Latent Thermal Energy Storage System
}

\author{
Kevin Merlin', Jérôme Soto², Didier Delaunay ${ }^{3}$, Luc Traonvouez ${ }^{4}$ \\ ${ }^{1,2,3}$ Laboratoire de Thermocinétique de Nantes, UMR 6607, CNRS, Université de Nantes, Nantes Atlantique Université \\ La Chantrerie, rue Christian Pauc, BP 50609, 44306 Nantes Cedex 3, France \\ kevin.merlin@univ-nantes.fr, didier.delaunay@univ-nantes.fr \\ ${ }^{1,2}$ Institut Catholique d'Arts et Métiers de Nantes \\ 35 Avenue du Champ de Manoeuvres, 44470 Carquefou, France \\ jerome.soto@icam.fr \\ ${ }^{4}$ Insula France \\ 57 rue des Vignerons, 44220 Couëron, France \\ contact@insula-france.com
}

\begin{abstract}
This paper presents the experimental performance of an industrial latent heat thermal energy storage. A demonstrator devoted to fatal energy recovery in food processing industry which can store $6 \mathrm{~kW}$.h of energy and develops a thermal power higher than $100 \mathrm{~kW}$ is investigated. The storage system is composed of an expanded natural graphite matrix impregnated with a Phase Change Material (PCM), allowing an increase of thermal conductivity of the PCM by a factor of 100. This kind of composite material have been studied in previous studies and appears to be one of the best solutions for applications requiring a high heat transfer density. The storage is used to recover the energy during the cooling phase of the process and this energy is used to contribute to the following cycle heating phase. An investigation of the heat transfer during cooling (heat storage) and heating (heat release) phases of the process and a performance study of the latent thermal storage are performed. The storage system is able to save up to $15 \%$ of the total energy of the process. However, differences appears between cooling and heating phases, and the possible causes of this phenomenon are presented.
\end{abstract}

Keywords: heat storage, phase change material, expanded natural graphite, industrial demonstrator

\section{Introduction}

This study focuses on energy saving using latent heat storage devoted to fatal energy recovery in industrial systems. Thermal storages have either a short, medium or long use; in order to focus on the most economically sound solutions, this work is carried out for short-term (1-4 hours) usage, which allows having at least 3 cycles of heat loading and heat unloading per day. Such applications can be for example cleaning textiles or glassware in front loading machines; in all cases it will be related to batch systems and not to continuous industrial processes. Due to both considerations of product safety and power demand, most of such batch processes use a set temperature in the form of a ramp during the heating and cooling phases. Working with ramps and a PCM-based thermal storage differs from publications using fixed set temperatures for the industrial processes. It is also closer to the actual applications of the industrial sector.

Latent heat storages provide a high energy density and consequently a reduced size in comparison with sensible heat storage. Cabeza et al. [1] studied the thermal performances and energy density of a storage using latent heat compared to sensible heat. Latent Heat Thermal Storage (LHTS) systems devoted to industrial applications have also been studied by some authors, such as Olivès et al. [2], Tamme et al. [3] or Wang et al. [4]. Usually, PCMs are used for medium or longterm uses due to low thermal conductivities, especially organic ones with values below $0.5 \mathrm{~W} \cdot \mathrm{m}^{-1} \cdot \mathrm{K}^{-1}$ [5]. However, some methods exist to improve the thermal efficiency of these materials. Medrano et al. [6] showed that the use of Expanded Natural Graphite (ENG) provides better performances in comparison to other methods, such as enhancing the heat exchange area (with finned or plate heat exchangers). This technique was also highlighted by Mehling et al. [7], showing that the heat transfer coefficient between this ENG/PCM composite material and a wall (electric heater) can reach values up to $3-5 \mathrm{~kW} . \mathrm{m}^{-}$ ${ }^{2} . \mathrm{K}^{-1}$, resulting in an decrease of the melting time (between 10 and 30 times faster). The thermal conductivity of the obtained composite material is also increased by a factor of 100 , with values between 20 and $25 \mathrm{~W} \cdot \mathrm{m}^{-1} \cdot \mathrm{K}^{-1}$, for an ENG volume 
fraction of $10 \%$. The thermal conductivity improvement of such a material was also investigated by Py et al. [8], as a function of the density of the ENG used. Many studies using a LHTS system incorporating an ENG/PCM composite material, have been conducted for various applications, as [9]-[15].

Similarly to Medrano et al. [6], a previous comparative study of various latent heat thermal exchangers has been carried out [16], and has shown that a composite material using an ENG matrix with a density of about $200 \mathrm{~kg} \cdot \mathrm{m}^{-3}$ and a paraffin is suitable to a short-term application. Based on these results, the design of a sterilizing industrial demonstrator of 6 $\mathrm{kW} . \mathrm{h}$ able to deliver a $100 \mathrm{~kW}$ thermal power is presented in the present study. This demonstrator has been built and implemented on an existing sterilizer. The thermal performance of such a storage system is investigated.

\section{Material and methods}

\subsection{Description of the sterilizer}

The aim of the project is to design a latent thermal storage for an industrial sterilizer. STERIFLOW is a French industrial company and world leader in the manufacture of batch sterilizers for food and pharmaceutical industries. Such sterilizers have a 3-6 $\mathrm{m}^{3}$ internal capacity, involving a high energy consumption per cycle. Furthermore, the number of cycles can exceeds 10 per day due to the short-term process (1-4 hours) of sterilization. In order to adapt an existing sterilization process, a smaller unit of 1-2 $\mathrm{m}^{3}$ is used at STERIFLOW's laboratory. The Sterilizer model is a Microflow $901 \mathrm{~S}$ from STERIFLOW, the cycle description of the thermal cycle of this sterilizer is provided in Fig. 1.a. This cycle can be divided in three phases, the first one is the heating process form the ambient temperature to a sterilizing temperature between 115 and $135^{\circ} \mathrm{C}$, depending on the product. This temperature is maintained during the sterilization process, corresponding to the second phase. Finally, a cooling phase is performed to decrease products' temperature allowing the batch replacement. The storage units are installed on the secondary loop (Fig. 1.b). We call primary loop, the circuit where the process overheated water is circulated. The primary loop is separated to the secondary loop, where superheated steam or cooling water are flowing, by a plate heat exchanger from Barriquand. The announced heat transfer coefficients of the heat exchanger are 2.9 $\mathrm{kW} \cdot \mathrm{m}^{-2} \cdot \mathrm{K}^{-1}$ in heating (vapour/water) and $2.3 \mathrm{~kW} \cdot \mathrm{m}^{-2} \cdot \mathrm{K}^{-1}$ in cooling (water/water). The storage system is designed to be used during the heating and cooling phases. In the first part of the heating phase, the storage units subsites the steam boiler. During this time, the PCM solidifies and stays at a quasi-constant temperature. When the HTF reaches a temperature near to the PCM melting temperature, the thermal power is not enough sufficient for the process. Thus, the LHTS circuit is by-passed and the traditional vapour system replaces the HTF to take over. During the cooling phase, the same principle is used, where the LHTS is used to cool the sterilization water while the PCM melts in the meantime, until the thermal power is not sufficient to satisfy the required cooling rate. A cooling circuit is then used to complete the process.

For the experiments carryout out, in order to simulate a real functioning with food cans or medical tools, the tests are performed with a tank filled of water within the sterilizer. We found, at the end of the experimental campaigns, that this water load was not properly kept at the same level for all test performed, involving a slight modification of the requesting power.

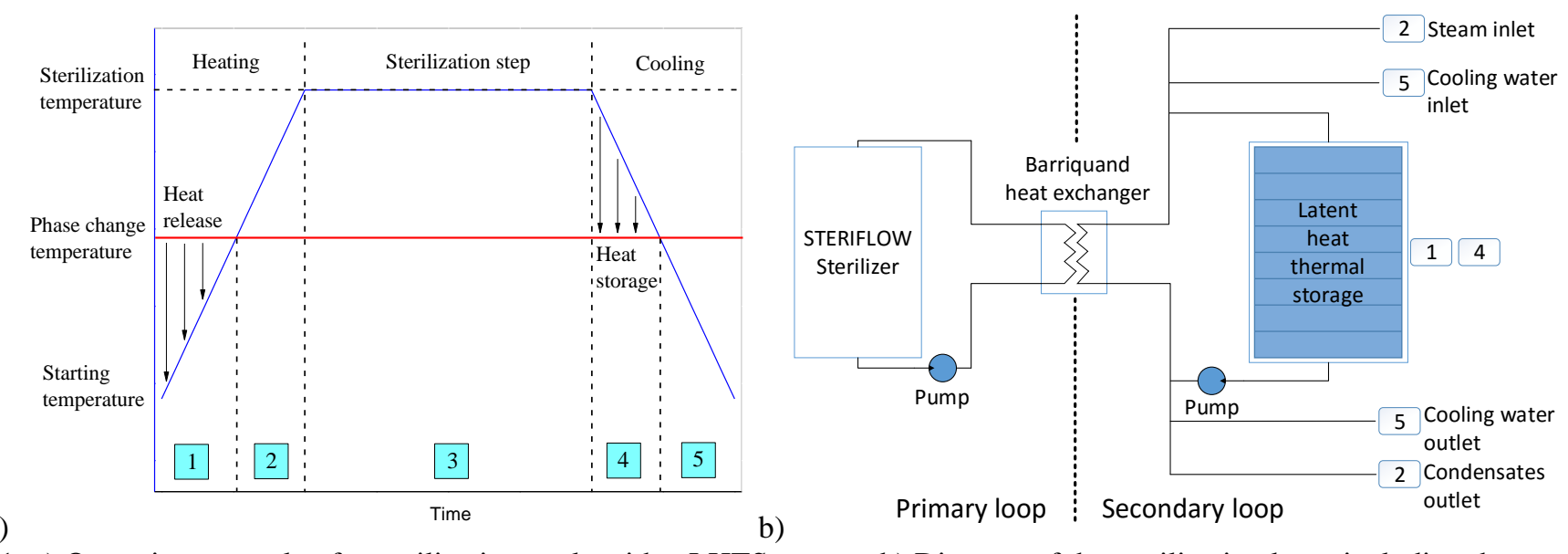

Fig. 1: a) Operating example of a sterilization cycle with a LHTS system. b) Diagram of the sterilization loop, including the secondary circuit with the LHTS system. 


\subsection{Description of the storage unit}

The phase change material used is a paraffin RT82 (provided by Rubitherm ${ }^{\circledR}$ Technologies $\mathrm{GmbH}$ ), which is selected for its melting/solidification range, between 60 and $82^{\circ} \mathrm{C}$, close to the average temperature of the HTF during cycle. The apparent specific capacity and the enthalpy variation of this PCM during heating (melting) and cooling (solidification) are respectively provided in Fig. 2.a and 2.b. This result is measured by a Differential Scanning Calorimetry (DSC), using a TA Instruments Q200. A summary of the thermophysical properties of this PCM is given in Table 1.
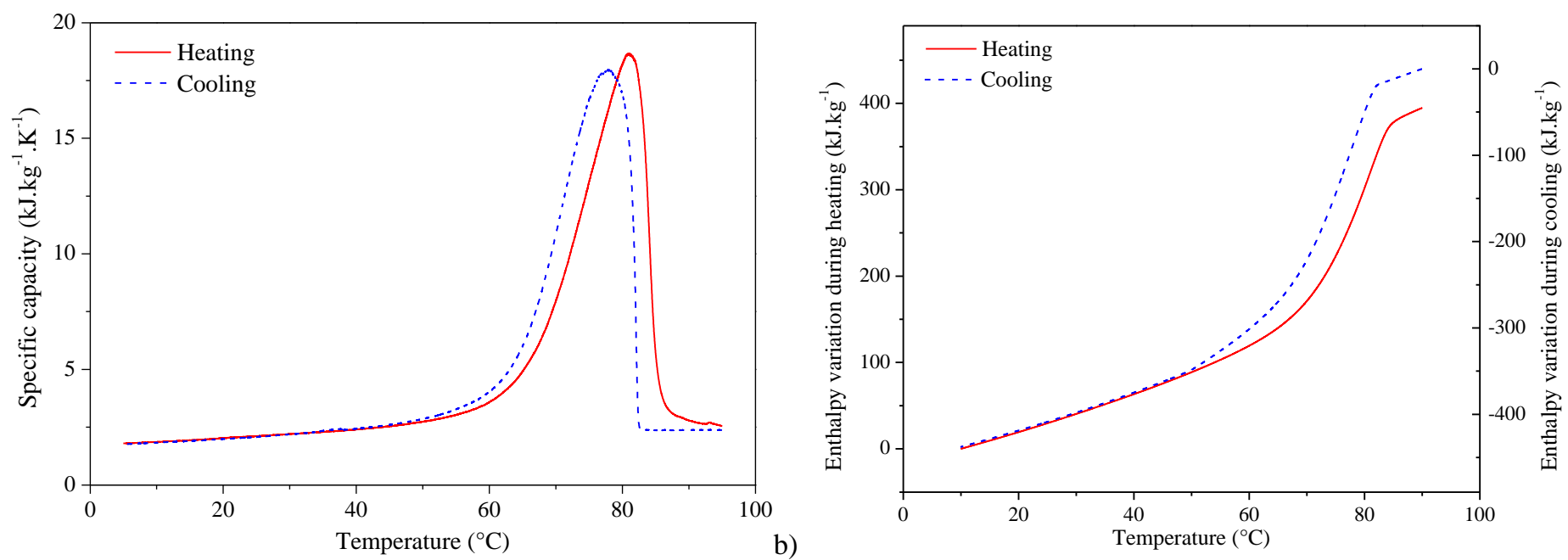

Fig. 2: a) Specific capacity measurement of the PCM during heating and cooling. b) Enthalpy variation of the PCM during heating and cooling.

Table 1: Thermophysical properties of the paraffin RT82.

\begin{tabular}{|c|c|c|c|c|c|}
\hline \multirow{2}{*}{ State } & Density* & Specific capacity & Phase change transition & Latent heat & Thermal conductivity* \\
\cline { 2 - 6 } & $\mathrm{kg} \cdot \mathrm{m}^{-3}$ & $\mathrm{~kJ} \cdot \mathrm{kg}^{-1} \cdot \mathrm{K}^{-1}$ & ${ }^{\circ} \mathrm{C}$ & $\mathrm{kJ}^{*} \mathrm{~kg}^{-1}$ & $\mathrm{~W} \cdot \mathrm{m}^{-1} \cdot \mathrm{K}^{-1}$ \\
\hline Solid & 880 & $2.00\left(\right.$ at $\left.20^{\circ} \mathrm{C}\right)$ & $55-88$ & 177 & 0.2 \\
\hline Liquid & 770 & $2.37\left(\right.$ at $\left.90^{\circ} \mathrm{C}\right)$ & $82.5-50$ & 193 & 0.2 \\
\hline
\end{tabular}

*Value from Rubitherm ${ }^{\circledR}$ Technologies GmbH

In order to enhance the thermal conductivity of this PCM, a porous matrix made of Expanded Natural Graphite is used. This kind of material allow to increase the thermal conductivity of the PCM by a factor of 100, for an ENG density of 200 $\mathrm{kg} \cdot \mathrm{m}^{-3}$ [7], [8], [16], without downgrading the storage capacity of the PCM [17]. The storage unit is designed to store $20 \%$ of the energy of a cycle, which represents an amount of $6 \mathrm{~kW} . \mathrm{h}$. A previous study of the composite material in a one meter length annular heat exchanger was performed and allowed to estimate a heat transfer coefficient between the heat transfer fluid and the composite material of $3 \mathrm{~kW} \cdot \mathrm{m}^{-2} \cdot \mathrm{K}^{-1}[16]$. The thermal power necessary to store/release the desired amount of energy is imposed by the cycle. The HTF needs to be heated from 35 to $130{ }^{\circ} \mathrm{C}$ within 15 minutes, corresponding to a thermal power maintained above $100 \mathrm{~kW}$. The following relationship is then used to estimate the required heat exchange surface:

$$
\begin{gathered}
S=\frac{P}{\mathrm{~h} \cdot \Delta T_{L M}} \\
\Delta T_{L M}=\frac{\Delta T_{o}-\Delta T_{i}}{\ln \left(\Delta T_{o}-\Delta T_{i}\right)}
\end{gathered}
$$

Where $\Delta T_{o}$ corresponds to the outlet temperature difference between the hot side and the cold side, and $\Delta T_{i}$ corresponds to the inlet temperature difference between the hot side and the cold side. In case of a heating cycle, the composite material is considered as the hot side and due to the latent behavior of this material, a constant temperature between the inlet and outlet of this side is taken. Moreover, an average input temperature difference between hot and cold sides of 
$20 \mathrm{~K}$ is considered. Thus, equation (1) is used to calculate the heat exchange surface and the value found is $2.5 \mathrm{~m}^{2}$. A numerical study using a 1D-finite difference model was used to investigate the melting front evolution as a function of the tubes diameter, in order to determine the space between two tubes. Finally, an external diameter of $12 \mathrm{~mm}$ (with $1 \mathrm{~mm}$ thickness) and a spacing of $52 \mathrm{~mm}$ are retained, corresponding to a bundle of 48 tubes per unit, for a total surface area of $2.95 \mathrm{~m}^{2}$.
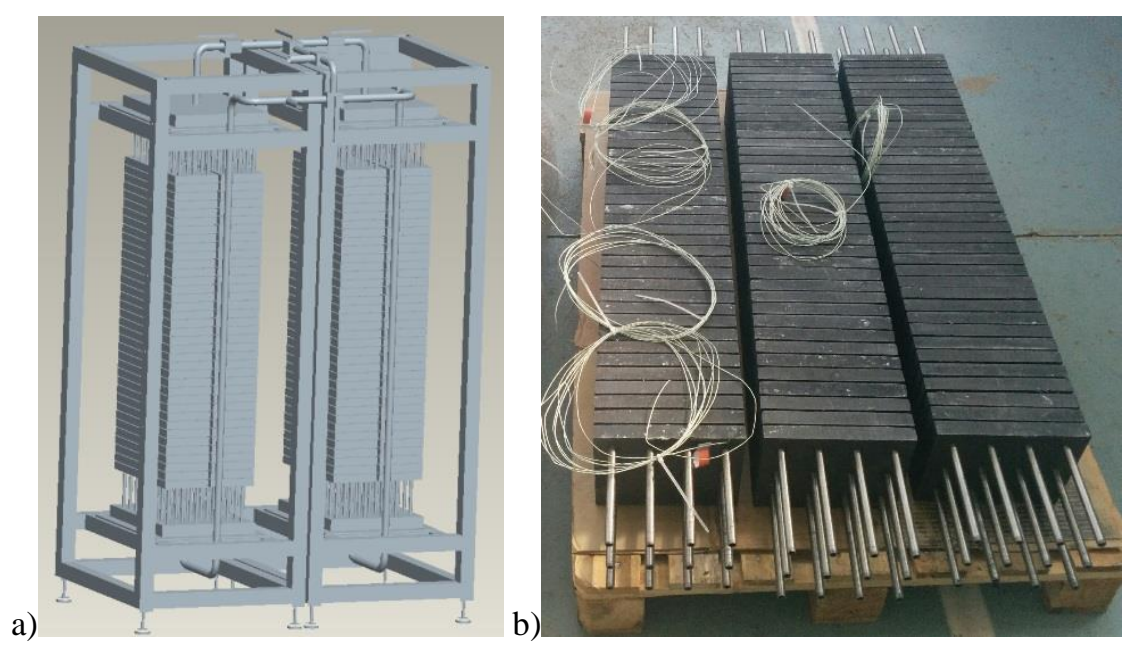

Fig. 3: a) CAD drawing of the storage system. b) Photo of the tube bundles through the composite plates.

The storage system is divided in two units, each unit is respectively composed of 148 composite plates, for a total amount of composite material of approximately $160 \mathrm{~kg}$ (see Fig. 3.a and 3.b). The storage unit is provided with a valve system allowing to by-pass the system, and to apply a series or parallel circulation in the two units.

In order to investigate the temperature distribution within the composite material, 17 thermocouples $\mathrm{K}$ are positioned in the LHTS. Two Pt100 sensors are used to measure the HTF inlet and outlet temperatures of the LHTS. The flow rate of the HTF is estimated by pressure drop measurement between inlet and outlet of the pump and using the pump manufacturer's data curves. All data are measured with an acquisition frequency of one point per second, apart from the pressure data with one point every five seconds.

\subsection{Thermal power and efficiency calculation}

The thermal power $\Phi$ of the storage system during energy storage or release is calculated using the HTF temperature difference between the inlet and outlet of the storage system, denoted $\Delta T_{\text {in } / o u t}$, the specific heat capacity $C p_{\text {fluid }}$ and the mass flow rate $\dot{m}_{\text {fluid }}$.

$$
\Phi=\dot{\mathrm{m}}_{\text {fluid }} \cdot C p_{\text {fluid }} \cdot \Delta T_{\text {in } / \text { out }}
$$

The amount of energy stored or released by the composite material during the period $\Delta t$ is calculated from the thermal power:

$$
\Delta Q(\Delta t)=\int_{0}^{\Delta t} \Phi(t) d t
$$

An efficiency coefficient is calculated in order to evaluate the performances of the LHTS, depending on the amount of recoverable energy by the LHTS system $\Delta Q_{\text {stored }}$ compared to the total amount of energy necessary to heat or cool the process water $\Delta Q_{\text {total }}$.

$$
\eta=\frac{\Delta Q\left(\Delta t_{P C M}\right)}{\Delta Q\left(\Delta t_{\text {total }}\right)}
$$


where $\Delta t_{P C M}$ and $\Delta t_{\text {total }}$ respectively refer to the operating time of the LHTS system and to the total heating/cooling time.

\section{Results and discussion}

\subsection{Data exploitation and thermal power calculation}

A typical evolution of the temperatures during a cycle is plotted in fig 5. The heating and cooling rates imposed are $6.7 \mathrm{~K} / \mathrm{min}$, which represent a heating and a cooling within 15 minutes with a beginning and ending temperature of $32^{\circ} \mathrm{C}$. Moreover, a sterilization temperature of $130^{\circ} \mathrm{C}$ is maintained during $2.5 \mathrm{~min}$. The set temperature and the measured temperature of the sterilization water are presented. The temperature of the HTF in the secondary loop is calculated as an average of the input and output temperatures of the HTF within the storage. The composite material temperature is the average temperature of each thermocouple within the storage. The cycle can be divided into five parts. The first two parts represent the heating process of the sterilization water. The first part refers to the storage system operating while the second part corresponds to the vapour heating. At the end of the first part, the thermal power provided by the composite material is not sufficient to respect the heating rate, resulting in a divergence between the set temperature and the measured temperature of the sterilization water. Thus, the storage system is by-passed and the vapour circuit is used to complete the heating of the process water up to $130^{\circ} \mathrm{C}$, where this sterilization temperature is maintained, corresponding to the third part. The last two parts correspond to the cooling process, where the PCM is used first until the thermal power is no longer sufficient and then cooling water is used to complete the cooling. During the heating and cooling, oscillation of the process water temperature can be observed around the set temperature. This is due to the regulation which is operated by switching on or off the circulating water pump or by opening or closing the steam valve.

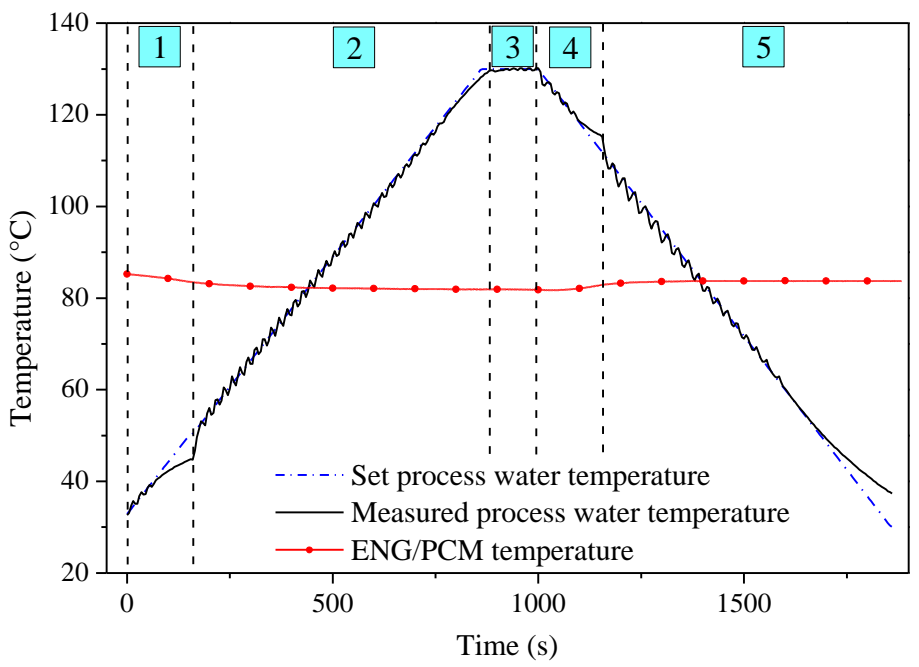

Fig. 5: Process water temperature and composite material temperature evolution during a cycle.

The heat transfer during heating using the LHTS system is detailed in Fig. 6.a. The set process water temperature, the measured process water temperature, the average HTF temperature of the secondary circuit and the average storage material temperature are plotted. The vertical dotted lines refer respectively to the beginning and to the end of the heating phase, using the LHTS system. The area denoted (a) represents the heat transfer from the composite material to the HTF, corresponding to the LHTS exchange, while the area denoted (b) is the heat transfer from the HTF to the process water, corresponding to the Barriquand heat exchanger. At the beginning, the large temperature difference between the HTF and the process water allows to obtain a higher thermal power than $100 \mathrm{~kW}$, requiring a flow rate regulation, which explains the oscillations of these two curves. At the end of this phase, the temperature difference between the HTF and the process water begins to slowly decrease, forcing the by-passing of the system to maintain a sufficient cooling rate. The same curves are also provided in Fig. 6.b for the cooling process of the process water, using the LHS system. Same observations can be done about the separation of the set and measured process water temperatures, but this phenomena is less pronounced than during the heating 
process and starts later. In both cases, the average composite material temperature remains at a constant temperature, slightly above $80^{\circ} \mathrm{C}$, showing that the heat transfer with the system is exclusively performed by latent heat.
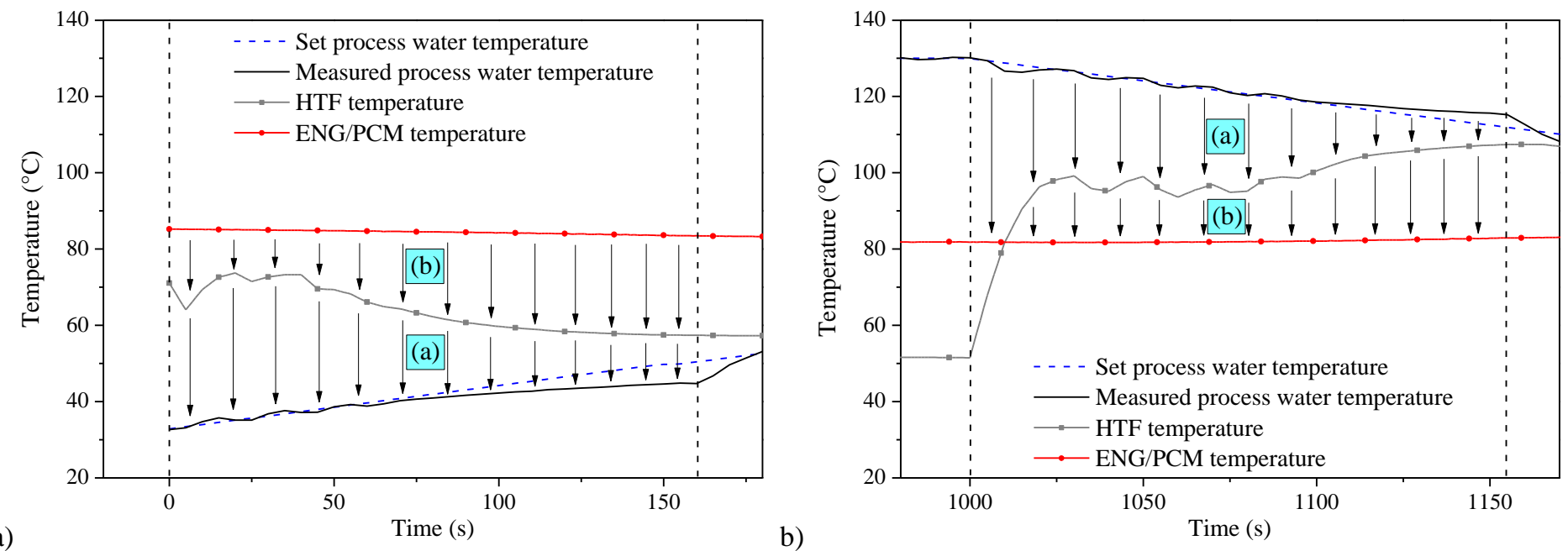

Fig. 6: a) Focus on the first phase of Fig. 5. b) Focus on the fourth phase of Fig 5.

The thermal powers during the charging and discharging process of the LHTS system, calculated by Eq. (3), are shown in Fig. 7, corresponding to the same test as above. In both cases, the thermal power is firstly higher than $100 \mathrm{~kW}$. This value corresponds to the power required to heat or cool the process water at the imposed heating/cooling rate. Therefore, mass flow regulation is performed using the pump to obtain the imposed heating/cooling rate, resulting in oscillations of the curves. Then, the thermal power goes below $100 \mathrm{~kW}$, corresponding to the separation between set and measured process water temperatures (Fig. 6.a and 6.b).

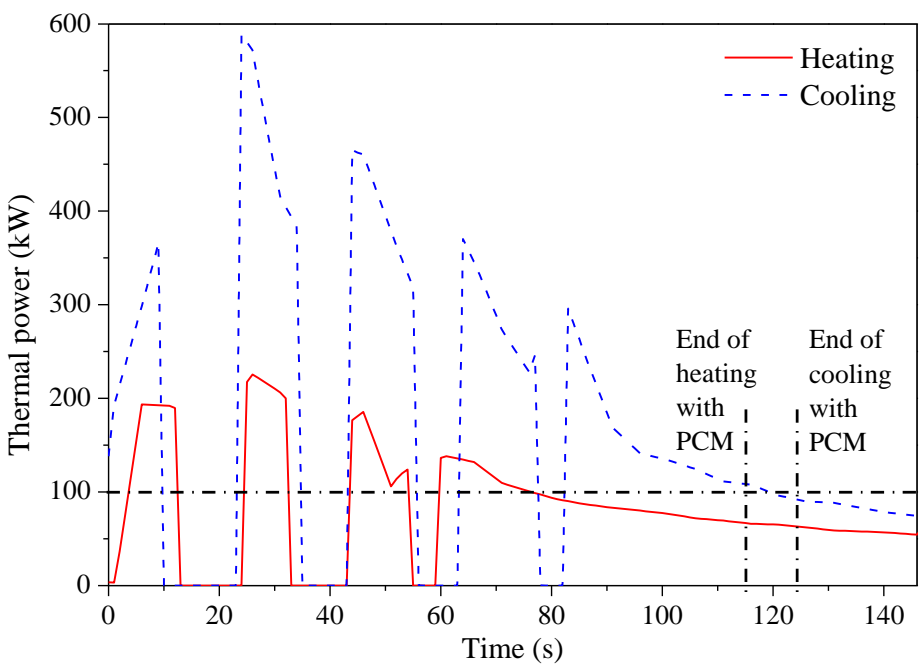

Fig. 7: Thermal power evolution during phases 1 (heating) and 4 (cooling) of the corresponding cycle (Fig. 5).

Similarly to the temperature curves, a difference appears between heating and cooling processes, where the thermal power is much higher in cooling than in heating, resulting in a better operating time in this case. This differences can be observed in all the tests, either in parallel or series circulation. They can be explained by various hypothesis. The first one is the temperature of the HTF, which influences strongly the viscosity and therefore the flowrate, resulting into a modification of the heat transfer. The second one concerns the impact of the thermal expansion of the composite material during melting/solidification which can lead to contact modification with the tubes and therefore a modification of the thermal exchange. Finally, the difference could be also due to thermal losses, which can easily unbalance the system, because after 
charging (cooling process) the hot system is much more affected by thermal losses than the cold system (after heating process).

Table 2: Summary of the energy exchanged and the average thermal power during heating and cooling with the LHTS for two identical cycles.

\begin{tabular}{|c|c|c|c|}
\cline { 3 - 4 } \multicolumn{2}{c|}{} & Run 1 & Run 2 \\
\hline \multirow{2}{*}{$\begin{array}{c}\text { Heating } \\
\text { process }\end{array}$} & Released energy (kW.h) & 3.4 & 3.5 \\
\cline { 2 - 4 } & Average thermal power $(\mathrm{kW})$ & 81 & 76 \\
\hline \multirow{2}{*}{$\begin{array}{c}\text { Cooling } \\
\text { process }\end{array}$} & Stored energy $(\mathrm{kW} . \mathrm{h})$ & 7.0 & 6.6 \\
\cline { 2 - 4 } & Average thermal power $(\mathrm{kW})$ & 124 & 129 \\
\hline
\end{tabular}

A summary of the thermal powers of all cycles is reported in Table 2. Same observations as above, concerning the differences between heating and cooling process are observed in the two identical tests. The total amount of stored/released energy is also calculated with respect to Eq. 4. Due to configuration differences and initial conditions, the tests show slight differences.

\subsection{State of the system after operation and efficiency analysis}

After the tests, an examination of the storage system revealed the good condition of the composite material, with a small leakage of paraffin and a sliding of the plates along the tubes. Initially, a gap between the plates was planned to anticipate the expansion of the composite material during melting, in order to prevent the plates from applying pressure on each other, leading to leakage. The sliding was already observed before the first tests. It was probably due to clearance between the tube and the composite material, and could have been reinforced by the transport of the system. Thus, during melting, the pressure applied by the plates on each other brought out a small amount of melted paraffin in excess. Moreover, the imperfect contact between the tube and the composite material could also have a significant impact on the heat transfer, which can be seen in the previous section.

The efficiency coefficients are calculated with respect to Eq. 5. Efficiencies are between 12 and $15 \%$ with better values in cooling processes due to higher thermal powers. This values are slightly lower than expected coefficients (around 20\%), the major reasons are the demanding power, higher than expected at the end of the heat transfer in the storage (energy still remaining) and the contact quality between the tube and the composite material, lower than in the study of the test bed [16].

\section{Conclusion}

A latent heat thermal storage system adapted to a sterilization process was designed, manufactured and tested. This storage is based on an expanded natural graphite matrix, impregnated with a phase change material: a paraffin RT82. The system is well adapted to actual industrial applications with short-term cycles, including set temperatures in the form of ramps during heating and cooling phases. The demonstrator reaches an efficiency of $15 \%$, corresponding to an energy of about $6 \mathrm{~kW}$.h. As planned, it is able to deliver a thermal power of at least $100 \mathrm{~kW}$ during heating and cooling phases, corresponding to a heating/cooling rate of $6.7 \mathrm{~K} / \mathrm{min}$, required by the sterilization process. However, differences on the thermal transfer appeared between heating and cooling phases. This is certainly mainly due to some assumptions, including the change of viscosity of the heat transfer fluid between the hot and cold phases or the variation of the thermal contact resistance between the tubes and the ENG/PCM composite material. During the operating time of the storage, the average composite material temperature remained at a constant temperature, slightly above $80^{\circ} \mathrm{C}$, showing that the heat transfer with the system is exclusively performed by latent heat, as expected. After several tests, a good condition of the demonstrator was observed. These results are encouraging for an industrial use, but the long-term stability of this solution still needs to be demonstrated.

\section{Acknowledgements}

This study was conducted in collaboration with STERIFLOW as part of the project MOSCA II, funded by the "Agence De l'Environnement et de la Maitrise de l'Energie" (ADEME) and TOTAL. The authors would like to thank STERIFLOW for having adapted their production model Microflow and for their participation in trials. 


\section{References}

[1] L. F. Cabeza, M. Iba, and C. Sole, "Experimentation with a water tank including a PCM module," Sol. Energy Mater. Sol. Cells, vol. 90, pp. 1273-1282, 2006.

[2] R. Olivès, X. Py, Q. Falcoz, P. Neveu, and J. Mancaux, "Intensification des transferts thermiques dans un module de stockage thermique: suivi du front de fusion par thermographie et simulation numérique," in Congrès Français de Thermique, 2014.

[3] R. Tamme, T. Bauer, J. Buschle, D. Laing, and W. Steinmann, "Latent heat storage above $120^{\circ} \mathrm{C}$ for applications in the industrial process heat sector and solar power generation," vol. 032736017, no. July 2007, pp. 264-271, 2008.

[4] W. Wang, S. Guo, H. Li, J. Yan, J. Zhao, X. Li, and J. Ding, "Experimental study on the direct/indirect contact energy storage container in mobilized thermal energy system (M-TES)," Appl. Energy, vol. 119, pp. 181-189, 2014.

[5] I. Dinçer and M. A. Rosen, Thermal energy storage - Systems and applications, 2nd ed. 2011.

[6] M. Medrano, M. O. Yilmaz, M. Nogués, I. Martorell, J. Roca, and L. F. Cabeza, "Experimental evaluation of commercial heat exchangers for use as PCM thermal storage systems," Appl. Energy, vol. 86, pp. 2047-2055, 2009.

[7] H. Mehling, S. Hiebler, and F. Ziegler, "Latent heat storage using a PCM-graphite composite material," in TERRASTOCK, 2000.

[8] X. Py, R. Olives, and S. Mauran, "Paraffin/porous-graphite-matrix composite as a high and constant power thermal storage material," Int. J. Heat Mass Transf., vol. 44, pp. 2727-2737, 2001.

[9] A. Greco, X. Jiang, and D. Cao, "An investigation of lithium-ion battery thermal management using paraffin/porousgraphite-matrix composite," J. Power Sources, vol. 278, pp. 50-68, 2015.

[10] J.-F. Luo, H.-W. Yin, W.-Y. Li, Z.-J. Xu, Z.-Z. Shao, X.-J. Xu, and S.-L. Chang, "Numerical and experimental study on the heat transfer properties of the composite paraffin/expanded graphite phase change material," Int. J. Heat Mass Transf., vol. 84, pp. 237-244, 2015.

[11] W. Wu, G. Zhang, X. Ke, X. Yang, Z. Wang, and C. Liu, "Preparation and thermal conductivity enhancement of composite phase change materials for electronic thermal management," Energy Convers. Manag., vol. 101, pp. 278$284,2015$.

[12] Z. Ling, J. Chen, T. Xu, X. Fang, X. Gao, and Z. Zhang, "Thermal conductivity of an organic phase change material/expanded graphite composite across the phase change temperature range and a novel thermal conductivity model," Energy Convers. Manag., vol. 102, pp. 202-208, 2015.

[13] A. Mills, M. Farid, J. R. Selman, and S. Al-Hallaj, "Thermal conductivity enhancement of phase change materials using a graphite matrix," Appl. Therm. Eng., vol. 26, pp. 1652-1661, 2006.

[14] V. Canseco, Y. Anguy, J. J. Roa, and E. Palomo, "Structural and mechanical characterization of graphite foam/phase change material composites," Carbon N. Y., vol. 74, pp. 266-281, 2014.

[15] F. Albouchi, M. Lachheb, M. Karkri, T. Ben Ameur, and S. Ben Nasrallah, "Investigation of a graphite/paraffin phase change composite," Int. J. Therm. Sci., vol. 88, pp. 128-135, 2015.

[16] K. Merlin, D. Delaunay, J. Soto, and L. Traonvouez, "Heat transfer enhancement in latent heat thermal storage systems: Comparative study of different solutions and thermal contact investigation between the exchanger and the PCM," Appl. Energy, vol. 166, pp. 107-116, 2016.

[17] A. Sari and A. Karaipekli, "Thermal conductivity and latent heat thermal energy storage characteristics of paraffin/expanded graphite composite as phase change material," Appl. Therm. Eng., vol. 27, pp. 1271-1277, 2007. 